\title{
Perception of Own Death Risk: An Assessment of Road-Traffic Mortality Risk
}

\author{
Henrik Andersson ${ }^{\star}$
}

\begin{abstract}
This study examines individuals' perception of their own road-mortality risk using a Swedish data set. Individuals' subjective beliefs about their personal risk are compared with the objective risk of his/her own age and gender group, which in this study is defined as the respondents' objective risk. Both descriptive statistics and regression results suggest that low and high risk groups over- and underassess their risk levels, respectively. Having access to individual-level data we also find that the probability of underassessment and the size of risk bias is related to individual characteristics, e.g. gender. Individuals' formation of risk perception is also analyzed based on the Bayesian learning model. Even though we find a positive relationship between perceived and objective risk, we cannot reject the hypothesis that individuals are not Bayesian in updating their risk beliefs.
\end{abstract}

KEY WORDS: Bayesian learning; Mortality risk; Peers; Road-traffic

\section{INTRODUCTION}

Individuals engage in risky activities on a daily basis, some of which they do voluntarily, like smoking or skiing, where for the latter the risk is part of the benefit of the activity. Other hazards are part of daily routines that cannot easily be avoided, e.g. eating or commuting to work or school. If individuals have accurate perceptions about risks, i.e. knowledge about the true levels of risks they face, they will be able to make well-informed decisions and expose themselves to an optimal risk level.

\footnotetext{
${ }^{1}$ Toulouse School of Economics (LERNA, UT1, CNRS), Toulouse, France

Corresponding address: Toulouse School of Economics (LERNA), 21 Allée de Brienne, 31000 Toulouse, France, henrik.andersson@tse-fr.eu
}

Numerous studies have examined individuals' perception of mortality risk $^{(1)}$, and the empirical evidence suggests that individuals misperceive mortality risks. This bias does not only influence individuals' ability to make well-informed decisions, it may also result in policy makers not allocating resources in an optimal manner, since they may base their decisions on objective risk measures or experts' assessments. Biased risk perception may also have an impact on preference elicitation. For instance, if individuals overassess mortality risks, monetary estimates of reducing mortality risks may be positively biased ${ }^{(2,3)}$. Hence, knowledge about individual risk perception is important not only 
from a research perspective, but also from a policy perspective.

Most studies of risk beliefs examine how individuals perceive the risk of different hazardous activities for a given population $^{(4,5)}$, and the evidence from them strongly suggests that individuals over- and underassess the probability of low and high risk events, respectively ${ }^{(5,6,7,8,9)}$. Benjamin and $\operatorname{Dougan}^{(10)}$ reexamined the data in Lichtenstein et al. ${ }^{(6)}$ and could not reject the hypothesis that risk perceptions were unbiased when they controlled for age cohorts. They suggested that risk perception would be more accurate for risks relevant to the individuals, i.e. the risk level of their own age group. Their findings were also supported by the results in Benjamin et al. ${ }^{(11)}$. Armantier ${ }^{(9)}$ questioned the results in Benjamin et al. ${ }^{(11)}$ and argued that they were due to an anchoring effect. Armantier concluded that the pattern in Lichtenstein et al. is a "salient and robust phenomenon" (p. 54), but also found evidence that supported the findings in Benjamin and Dougan ${ }^{(10)}$ that individuals perceive the risk of their own age group more accurately.

The Bayesian learning framework has been used to analyze this robust finding of over- and underassessment of low and high level risks. The framework provides an analytical tool to examine how individuals' form their risk perceptions ${ }^{(5,12)}$ and it has shown that the over- and underassessment found is in line with a rational learning process ${ }^{(13,4)}$. Since risk information is both costly and limited, individuals will only partly acquire the information on risk levels and the risk bias will persist. Hakes and Viscusi(5) and Andersson and Lundborg(14) extended the analysis based on the Bayesian learning framework by using individuallevel data. This enabled them to examine how individual risk perception and bias are affected by socio-economic and demographic factors. Based on their analysis they found that several socio-economic and demographic attributes, for instance education, income, health status and gender, indeed influenced individuals' risk perception.

As explained, most previous research on risk perception has focused on differences between perceived and objective population risks. Andersson and Lundborg $^{(14)}$ extended the analysis of mortality risk perception and instead examined how individuals perceive mortality risks to themselves. They studied two risks, road-traffic and overall mortality risk, and found a similar pattern to the one in the literature on population risks for road-traffic mortality, i.e. an over- and underassessment for low and high risk groups, respectively. For overall mortality risk they found that all groups underassessed the risk. Based on evidence that individuals are more optimistic about risks that they can control, Andersson and Lundborg(14) assumed that they would be more likely to underassess road-traffic risk. The finding of a systematic optimism bias for overall but not road-traffic risk was, therefore, contrary to what they expected. 
In this study we further examines individuals' perception of their own mortality risk by employing the Bayesian learning framework on a Swedish data set. This data set contains individual-level data on the perception of own road-traffic mortality risk and socio-economic and demographic characteristics. Our aim is to analyze individuals' perception of their own road-traffic mortality risk and our specific objectives are to examine if: (i) perceived risks differ from objective risks, (ii) the probability of underestimation varies in terms of demographic characteristics, (iii) there is any correlation between the magnitude of bias and individual characteristics, and (iv) the risk perception formation of own risk follows the pattern found in Lichtenstein et al. ${ }^{(6)}$. We follow the standard in the literature and use the probability of death as the measure of the objective risk. The objective risk of a specific individual is defined as the objective risk of the respondents' peers (i.e. their own gender and age group). This definition of objective risk follows the one in Andersson and Lundborg ${ }^{(14)}$ and since the risk perception question has been framed in the same way in this and their study we are able to examine how robust the findings in Andersson and Lundborg ${ }^{(14)}$ are. Since Andersson and Lundborg ${ }^{(14)}$ differ from previous research by examining individuals' own risk, and since their finding regarding optimism bias was contrary to expectations, it is of importance to examine if the findings in Andersson and Lundborg ${ }^{(14)}$ are robust.

The paper is structured as follows. The following section briefly reports on previous findings in the empirical literature on mortality risk perception, and describes the Bayesian learning model. We thereafter describe the data set used. Descriptive statistics and regression results are then shown in section 4 . We discuss and relate our results to Andersson and Lundborg ${ }^{(14)}$ in section 5, before concluding the study in section 6 .

\section{RISK PERCEPTION}

\subsection{Empirical findings}

It is well established that lay people's subjective risk beliefs differ from objective risk measure ${ }^{(15,16)}$. Reasons for this difference are individuals' known difficulties of judging small probabilities ${ }^{(17,18)}$, and that lay people are more influenced in their perceptions by media coverage, own experience, etc., of the hazards ${ }^{(19)}$.

The empirical evidence also suggests that individual characteristics influence risk beliefs, and one characteristic that has been thoroughly examined is gender. There is strong evidence that females perceive risky activities as more dangerous than males do ${ }^{(20,21,22,23,24,25,26,27)}$. The reason for this gender difference has been debated, and suggestions that the difference is biological, or that women are less informed than men, have been questioned ${ }^{(28,29,30,31,32)}$. Plausible explanations are rather that women dislike risk more than men ${ }^{(33,34,35)}$ and that men often have more to gain from risky activities ${ }^{(23)}$.

Other attributes that have been shown to 
influence risk perception are age, income level, and education. Whereas the effect of age varies with the type of hazard ${ }^{(25,36)}$, income and education level seem to reduce the individual perception of risk $^{(21,25)}$. There is also evidence suggesting that the more educated have a more accurate risk perception $^{(5)}$. Further, it has also been found that the presence of children in the household ${ }^{(25,23)}$ and negative experience of the hazardous activity $(36,37)$ increase the risk perception.

This study examines individuals' perception of their own traffic-mortality risk. The empirical evidence would suggest that individuals will underassess this risk for two reasons: (i) exposure to the risk is to some degree voluntary, which means that it is perceived as less "troublesome" compared to involuntarily incurred risks ${ }^{(15)}$, and (ii) optimism bias is known to be greater for risks to oneself and risks that are perceived controllable by one's own actions ${ }^{(38)}$. Based on other empirical evidence, we also expect the optimism bias to be larger for men than for women ${ }^{(39)}$, and larger for younger than for older male drivers ${ }^{(37,40)}$.

Andersson and Lundborg ${ }^{(14)}$ did not find any support for a systematic optimism bias, the sign and size of the bias depended on gender and age. The empirical evidence on risk perception and traffic risk suggests a dependence on age and gender, with females and older respondents having a higher perception of risk ${ }^{(41,42)}$. Research also suggests that individuals' perception of the risk of their own age group is more accurate that their perception of population risks or the risk of other groups $(9,10,11,41)$. Hence, based on the empirical evidence, we expect females to be more likely to overassess their risk, whereas the optimism bias is likely to be the largest for young males.

\subsection{Bayesian risk formation}

Numerous studies have found evidence suggesting that individuals update their risk perception in a Bayesian manner ${ }^{(2,4,13,20,36,43,44)}$. The Bayesian learning model is outlined in several other papers ${ }^{(45,46)}$ and for reasons of brevity the description of the model is kept short here.

The basic concept of the Bayesian updating process is illustrated in Figure 1. Individuals' prior risk beliefs are represented by the horizontal line. When they obtain new information, for instance through campaigns or their own experience, they update their beliefs. If the new information resulted in perfectly informed individuals, the perceived risk would be represented by the 45 degree line. However, empirical evidence suggests that learning is only partial, and, hence, individuals overassess and underassess low and high probability events, respectively, as represented by the unbroken line ${ }^{(5,6,9)}$.

[Figure 1 about here.]

New risk information may take different forms. We follow Viscusi ${ }^{(20)}$ and assume that the individuals' risk beliefs are determined by three sources of information; prior risk assessment $(q)$, experience $(a)$, 
and "specific risk information" $(r)$. Experience refers not only to experience of risky activities, but also to demographic and socio-economic characteristics that can be assumed to influence the individual's experience of the risks, e.g. gender or wealth level. Specific risk information refers to information about risks that the individual is exposed to, e.g. campaigns about the risk of smoking, media coverage of earth quakes, or information on safety rankings of cars.

Based on the information sources above, the individual's risk beliefs may be defined as a weighted average of these sources,

$$
p=\frac{\lambda_{1} q+\lambda_{2} a+\lambda_{3} r}{\lambda_{1}+\lambda_{2}+\lambda_{3}}
$$

where $\lambda_{1}, \lambda_{2}$, and $\lambda_{3}$ denote the information content associated with $q, a$, and $r$, respectively. To illustrate, assume that $\lambda_{3}=0$, i.e. the individual assign zero weight to information about risk $(r)$, then the individual's risk perception will be a function of prior beliefs $(q)$ and own experience $(a)$. Now let $\theta_{i}=\lambda_{i} /\left(\lambda_{1}+\lambda_{2}+\lambda_{3}\right), i \in\{1,2,3\}$, then Eq. (1) may be written as,

$$
p=\theta_{1} q+\theta_{2} a+\theta_{3} r
$$

Equation (1) may be used to predict how new and/or changes in information content affect individual risk perception. For instance, by differentiating Eq. (1) with respect to $\lambda_{3}$ we can predict how a change in the informational content associated with risk information affects the individual's risk perception,

$$
\frac{\partial p}{\partial \lambda_{3}}=\frac{\lambda_{1}(r-q)+\lambda_{2}(r-a)}{\left(\lambda_{1}+\lambda_{2}+\lambda_{3}\right)^{2}}
$$

and, thus,

$$
\frac{\partial p}{\partial \lambda_{3}}>0 \text { if } r>\frac{\lambda_{1} q+\lambda_{2} a}{\lambda_{1}+\lambda_{2}}
$$

Equation (4) predicts that if the individual's experience of the risk and prior beliefs are lower than the specific risk information, then the perceived risk will increase as a result of the individual assigning more weight to the risk information.

\section{STUDY DESIGN AND DATA}

The data originate from a contingent valuation (CVM) survey conducted in Sweden in the fall of 2006. The aim of the survey was to elicit respondents' preferences for food and car safety, i.e. their willingness to pay (WTP) to reduce the risk of these activities. This study only analyzes the information from the survey on the respondents' risk perception. $^{2}$

The CVM survey was distributed to 1,898 randomly chosen individuals as a postal questionnaire. A total of 34 surveys could not be delivered because of "recipient unknown" (e.g. the respondents had moved or the address was incorrect), and after two reminders a 49.4 percent response rate was achieved, i.e. $n=920$. The respondents received a paper copy of the questionnaire, but were also informed in the accompanying covering letter that they had the option to complete the questionnaire on the web. Only 49 respondents chose that option, and

\footnotetext{
${ }^{2}$ The respondents' preferences for food and car safety are analyzed in Sundström and Andersson (47) and Andersson et al. ${ }^{(48)}$, respectively.
} 
thus, with few exceptions, observations were from respondents answering the paper questionnaire. ${ }^{3}$

The questionnaire consisted of five sections. The first section contained questions mainly related to food safety with a focus on risk perception, handling, experience, etc. In the second section the respondents faced an evaluation example. The aim of this section was to train respondents in trading wealth for safety. In order to communicate the risk and to help respondents understand the magnitude of the risk, a visual aid, in the form of a grid consisting of 10,000 white squares with the risks visualized as black squares, was included in this section ${ }^{(49)}$. The respondents were informed that the blackened squares represented the risk level and they were also presented with the actual probabilities the blackened squares represented. The third section contained the WTP question for food safety, and again the same visual aid was used to communicate the baseline and the change of the risk levels. The fourth section of the questionnaire focused on car safety, whereas the fifth and final section asked follow-up questions on demographics and socio-economics.

The question about individual risk perception used in this study was asked in the fourth section. In order to test for framing effects on respondents' WTP for car safety, two versions of the questionnaire were constructed; one subsample with a monthly scenario, and the other subsample with an annual

\footnotetext{
${ }^{3}$ For a fuller description of the survey and the subgroups, see Sundström and Andersson ${ }^{(47)}$.
}

scenario. Thus, baseline risks, risk reductions, and payments were adapted to the time frame given. For this study the answers to the monthly scenario have been converted to annual values.

At the beginning of the section on car safety, the respondents were informed that (freely translated from Swedish):

The annual average risk of a fatal car crash is 7 in 100,000. The risk, though, is not only related to the characteristics of the car itself, and we would, therefore, like to ask some questions about your background as a driver/passenger.

The annual average risk level was estimated as the ratio between the number of annual fatalities in cars and the number of cars in use. This risk measure, which is not a probability measure but a risk ratio since it can be larger than one, has been used in hedonic price-risk studies in the car market to elicit individuals preferences for car safety ${ }^{(50,51,52)}$. Its level is close to the population road-mortality risk in Sweden, 6.42 per 100,000 (see Table II ), and we believe it to be a good proxy for road-mortality risk. Hence, we use the respondents' answers about car-mortality risk as a proxy for road-mortality risk, and from now on the subjective risk in this study is defined as the population road-mortality risk.

After being presented with the information above, the respondents were then asked questions about whether they had a driving licence, access to a car in the household, driving or travelling distance by car and traffic injury experience, before they were asked about their own perceived mortality risk. This question was framed as follows: 
If the annual average risk of dying as a result of a car crash is 7 in 100,000, what do you think is your own annual risk of dying as a result of a car crash?

I think that the risk is ...... in 100,000.

As explained above, to improve respondents' understanding of the probability levels, the visual aids were used twice in the survey. Since the visual aids had been presented twice to the respondents before the WTP scenario on car safety, it was decided that it was not necessary to include the grid in that section as well.

\section{RESULTS}

\subsection{Descriptive statistics}

The descriptive statistics of the survey are shown in Table I . The last column shows mean values of the general Swedish population of the relevant age group (18-74) for variables chosen to examine the representativeness of the sample. Besides the proportion of female respondents, which is higher compared with the general population, 59.6 vs. 49.6 percent, our sample appears to be representative of the general Swedish population. The high share of female respondents is assumed to be a result of the fact that the first half of the survey concerned food safety. Swedish women are still responsible for most of the household food production $(>60 \%)^{(53)}$, and may therefore have a higher interest in food safey. Self-reported health status was obtained by asking respondents to mark their perceived health status on a visual analog scale in the form of a thermometer ranging from 0 to 100 , where 100 was the best imaginable health state ${ }^{(54)}$.

[Table I about here.]

Objective and perceived risks for age groups and gender are shown in Table II . Objective risks are based on the number of fatalities over 8 years, i.e. 1999-2006. Per 100,000, the overall mortality risk is 6.42 , and 2.96 and 9.86 for women and men, respectively. Table II also reveals that men have a higher mortality risk for all age groups, and that the mortality risk follows a U-shape over the life cycle. That men are more likely to die in road traffic and that the objective mortality risk is U-shaped over age are not unique for Sweden ${ }^{(55)} .4$ From an international perspective, the road-mortality risk is relatively low in Sweden. ${ }^{5}$

[Table II about here.]

Regarding perceived mortality risk, about half of the respondents stated that their own risk was lower than the average objective risk. However, due to a small number of large values, the estimated perceived arithmetic mean in Table $\mathrm{I}$ is higher than the objective risk. In order to decrease the distorting effect of outliers among respondents' answers, we follow previous studies and focus on geometric means ${ }^{(5,14)}{ }^{6}$ The geometric means of perceived risk in Table II reveal that: (i) all female

\footnotetext{
${ }^{4}$ See, e.g., TrafficStats (http://www.traffic-stats.us) and/or $C A R E$ (http://ec.europa.eu/transport/roadsafety/).

${ }^{5}$ See, e.g., references in previous footnote.

${ }^{6}$ Arithmetic means are shown in Table VI in the appendix.
} 
age groups, besides the youngest one, overassess their risk, (ii) all male age groups underassess their risk, and (iii) when men and women are grouped together only the age group with the lowest objective risk overassesses its risk, i.e. the age group 4554. Most of the differences between objective and perceived risks are statistically significant. Regarding overall means we find that males perceive their risk to be higher than females but the difference is not statistically significant. Moreover, females and males over- and underassess their risks, respectively, and the full sample underassesses the mortality risk. These differences are statistically significant. A scatter plot of the distribution of respondents' perceived road-mortality risk can also be seen in Figure $2 .^{7}$

[Figure 2 about here.]

\subsection{Regression results}

This section contains the regression results in the following order; a probit model on the probability of underassessment, an OLS model on the absolute magnitude of risk bias, and an OLS model on risk formation. ${ }^{8}$

The results of the probability of underassessment are shown in Table III . The coefficient estimates

\footnotetext{
${ }^{7}$ To make the scatter plot more informative, only observations lower than 40 per 100,000 are shown in Figure 2. This means excluding the answers from 32 respondents from the figure, of which 6 respondents stated that their road-mortality risk was between 1 and 20 percent.

${ }^{8}$ Since the probit and OLS are well known, we have not included a description of the empirical models. For a description of the models, see any textbook on econometrics.
}

show the marginal effect and reveal that women are less likely to state that their risk is lower than their peers (i.e. same gender and age group), that Annual mileage is negatively related to the perceived risk being lower than the objective risk, and that those who have a driving licence are less likely to state that their risk is lower than their peers. ${ }^{9}$ Thus, two of the variables related to road traffic experience are significantly negatively correlated with underassessment. Moreover, the number of children in the household aged 11-17 are also statistically significantly correlated with underassessment. Further, we find that Income is not statistically significant, a result that is also found when household income is instead included as a group variable. ${ }^{10}$

[Table III about here.]

Two regressions on the magnitude of risk bias

${ }^{9}$ The coefficient estimates in Table III denote marginal effects. Let $\Phi(\cdot), \phi(\cdot), x, \bar{x}$, and $\beta$, denote the standard cumulative normal distribution, normal density function, explanatory variables, mean value, and coefficients, respectively; then the marginal effects are calculated as:

$$
\frac{\partial \Phi(x \beta)}{\partial x_{1}}=\phi(\bar{x} \beta) \beta_{1} .
$$

${ }^{10}$ Table VII in the appendix shows results from a multinomial logistic regression, where the probability of over- and underassessment is analyzed simultaneously. We have decided to use the probability of underassessment in Table III as our main results for two reasons: (i) the probability of underassessment was estimated in Andersson and Lundborg(14) and one objective of this paper is to test the robustness of their findings, and (ii) since we do not have any information about a reasonable band width for an accurate risk perception, chosen band widths will be ad hoc. In Table VII results are shown for the case when accurate perception is defined as Perceived $\epsilon$ [Obj. $-1, \mathrm{Obj} .+1]$. The robustness of the results has been tested by running regressions with band widths 1.5 and 2 . Besides Driving licence in "Underassessors" and Female, the results are sensitive to the chosen band widths. 
were run; one for those respondents who stated that their risk was lower than the objective risk, and one for those respondents who stated that their risk was equal to or higher than the objective risk. The results are shown in Table IV and for those respondents who perceived their risk level to be equal to or higher than their peers, no variables are statistically significant. For the other group, the bias is larger for younger respondents (reference group, Age 18-24), but the bias is not monotonically decreasing with age. The bias is also smaller for females, and for respondents with a university degree.

[Table IV about here.]

Table $\mathrm{V}$ shows the results of risk perception formation. Since we only have cross sectional data, we do not have any information about prior risk assessment. The first term of Eq. (2) is, therefore, reflected by the intercept. We employ the same functional form as Hakes and Viscusi ${ }^{(5)}$ and Andersson and Lundborg ${ }^{(14)} \cdot{ }^{11}$ To clarify, if respondents were fully informed, the intercept would be zero, and the coefficients of $\ln$ (Objective Risk) and $\ln$ (Objective Risk) $)^{2}$ would be one and zero, respectively. The results in Risk model 1, i.e. with other covariates excluded, show that the intercept is statistically

\footnotetext{
${ }^{11}$ Perceived and objective risks were transformed by the natural logarithm and a quadratic term of the objective risk was included to allow for non-linearity. This resulted in the following functional form,

$\ln ($ Road Mortality $)=\alpha_{0}+\alpha_{1} \ln (O R)+\alpha_{2} \ln (O R)^{2}+\mathbf{Z \Gamma}+\varepsilon$, where $O R$ is the objective risk, $\mathbf{Z}$ and $\boldsymbol{\Gamma}$ denote vectors of individual characteristics and coefficient estimates, respectively, and $\varepsilon$ is the residual.
}

significant, whereas both objective risk variables are not statistically significant. When including the other covariates in Risk model 2, the risk variables are still statistically insignificant and the intercept is now also statistically insignificant. A joint test of the intercept and $\ln$ (Objective Risk) ${ }^{2}$ being zero, and $\ln$ (Objective Risk) being one, is rejected ( $\mathrm{p}$ val. $<0.001)$ for Risk model 1 and Risk model 2. The results from Risk model 1 suggest that the cut-off point for over- and underassessment is $4.68 \cdot 10^{-5}$. In Risk model 2, the only covariates that statistically influence the risk perception are University, Household 0-3, and Driving licence. All three variables increase the perceived risk.

[Table $\mathrm{V}$ about here.]

We do not find any statistically significant correlation between perceived and objective risk. However, the coefficient estimates from Risk model 1 show that the partial derivative for the range of the respondents is between -0.16 and $0.55 .^{12}$ The slope is zero at the risk level $3.7 \cdot 10^{-5}$ and the slope at the mean objective risk is 0.19 . The slopes at the mean and for the highest risk group (men aged 2024 ) suggest that 0.19 and 0.55 of the risk information is incorporated at these levels, respectively.

\section{SUMMARY AND DISCUSSION}

This study analyzes individuals' perception of their own road-mortality risk. Using data from a

$12 \frac{\partial \ln (\text { Perceived })}{\partial \ln (\text { Objective })}=\alpha_{1}+2 \alpha_{2} \ln ($ Objective $)$ 
new Swedish CVM study, it replicates the analysis in Andersson and Lundborg(14) in order to test the robustness of their results. We find that some but not all the results are robust. ${ }^{13}$

Our results suggest that low and high risk individuals over- and underassess their own roadmortality risk, respectively. This finding is line with the results in Andersson and Lundborg(14) and the empirical evidence on population mortality risks, i.e. over- and underassessment of low and high probability events, respectively ${ }^{(5,6)}$. Considering gender and age, our results show that males underassess their road-mortality risk, whereas all females, besides the youngest age group, which has the highest objective risk among females, overassess their road-mortality risk. Moreover, for three of the female age groups, $18-19,20-24$, and 65-74, the perceived mean is close to and not statistically significantly different from the objective risk. Further: (i) overall subjective risk is statistically significantly lower than objective risk, (ii) males perceive their risk to be higher

${ }^{13}$ The question in Andersson and Lundborg (14) differs slightly from the one in this study. Their question explicitly asked respondents to think about their behavior and was stated as follows:

In an average year the risk of dying in a traffic accident for an individual in her/his $50 \mathrm{~s}$ is 5 in 100,000. What do you think your own annual risk of dying in a traffic accident will be? Your risk may be higher or lower than the average. Consider how often you are exposed to traffic, what distances you travel, your choice of transportation mode and how safely you drive.

I think that the risk is ..... in 100,000.

Since this study asked respondents about own behavior before the question about their own risk, we believe that the two questions are comparable. A direct comparison of the results is therefore possible and useful. than females but the difference is not statistically significant, (iii) males overall underassess their risk, and (iv) females overall overassess their risk. The findings (i)-(iii) are in line with Andersson and Lundborg ${ }^{(14)}$. Regarding (iv), female respondents in Andersson and Lundborg ${ }^{(14)}$ also overassessed their risk, but in their study the overassessment was not statistically significant.

The regression on the probability of underassessment shows, as expected based on the descriptive statistics, that females are less likely to underassess their risk. We also find that Annual mileage is negatively correlated with underassessment. Both these results support the findings in Andersson and Lundborg ${ }^{(14)}$. We also find that respondents with a driving licence are less likely to underassess their road-mortality risk. Information about whether the respondents had a driving licence was not available in the data set used in Andersson and Lundborg(14), but the results of this study combined with the results of both studies suggest that Annual mileage and Driving licence may be proxies for risk exposure rather than skill or experience.

Regarding the size of the bias in respondents' risk perception, whereas no individual characteristics are statistically significantly correlated with the size of the bias for respondents with a subjective risk higher than or equal to the objective risk, age, gender, and a university degree are negatively correlated with the size of the bias for underassessors. The age reference group is respondents aged $18-24$ and since the refer- 
ence group in Andersson and Lundborg ${ }^{(14)}$ was 45-54 a direct comparison of the age effect is not relevant. The reason why age 45-54 was used in Andersson and Lundborg ${ }^{(14)}$ was because respondents in their study were informed about the objective risk of a 50 year old person. In our study respondents were informed about the population risk. We find that respondents with a university degree have a smaller bias among underassessors, a result not found in Andersson and Lundborg(14). Regarding the results of other covariates in Andersson and Lundborg(14); males' risk bias was larger for both groups, Health status was statistically significant with different signs, and Annual mileage negatively and Income positively influenced the risk bias among under- and overassessors, respectively. Hence, besides the gender effect among underassessors, the results differ.

In the regression on the formation of risk perception, we find no statistically significant correlation between perceived and objective risks. Thus, we cannot reject that individuals do not update their risk perception in a Bayesian manner. However, the partial derivative, which ranges from -0.16 to 0.55 , suggests a positive relationship between perceived and objective risks above the baseline risk level of $3.7 \cdot 10^{-5}$. These results are also close to those in Andersson and Lundborg ${ }^{(14)}$, where the partial derivative ranged from -0.25 to 0.55 , with a positive slope above the risk level $3.8 \cdot 10^{-5}$. Regarding other covariates, having a university degree, children aged $0-3$, and a driving licence increase the perception of risk. These results differ compared to the results in Andersson and Lundborg ${ }^{(14)}$, where self-reported health status, being male and having children aged 417 reduced the risk perception, whereas income level increased it.

\section{CONCLUSIONS}

Many of the findings in this study support the results in Andersson and Lundborg ${ }^{(14)}$. Over- and underassessment for low and high risk groups are confirmed, and the Bayesian updating process based on objective risk reveals similar values between the studies. The effect of individual characteristics on the probability of underassessment, size of risk bias, and risk formation for several variables differs, however, between the studies. The result that females are more likely to overassess their own mortality risk, and that individuals who drive or travel more by car are less likely to underassess their risk is robust, though.

Andersson and Lundborg (14) examine two mortality risks, road and overall. They assumed that individuals would perceive road-traffic risk to be more controllable than overall risk, and thus to be more affected by optimism bias. Their results that road-mortality risk followed the pattern of over- and underassessment, whereas all groups underassessed overall mortality risk, therefore contradicted their expectations. Since our results confirm their findings on road-mortality risk, it may be that individuals perceive road risk as more exogenous, whereas they perceive their overall risk to be more under their own 
control. This could be explained by the fact that road risk is affected by exogenous factors, such as other road-users, weather conditions, etc., whereas overall risk to a large extent is determined by individual health factors, which can be influenced by decisions on smoking, exercising, etc.

A weakness of our analysis is that the objective risk is based on overall road-mortality risk, whereas the respondents in the CVM study were presented with and asked about car-mortality risk. The risk measure in the CVM questionnaire was, however, designed such that it would correspond closely to the road-mortality risk, i.e. the annual car risk ratio of 7 is close to the road risk of 6.42 per 100.000 . Moreover, the respondents in Andersson and Lundborg(14) were asked about their perception of road-mortality risk, and the fact that the patterns of risk bias and formation found in their study are supported by the results in this study suggests that the formulation may not be a crucial or decisive weakness.

The results of this study are of relevance to both policy makers and those who study risk behavior. Since individuals base their decisions on their perceived risk, our findings are important for understanding risky behavior ${ }^{(12,56,57,58)}$. Hence, it is important to know how individuals perceive their own risk, not only how they perceive risk for the population at large. Moreover, regulatory bodies, such as environmental or health protection agencies, have been found to be influenced by the public's perception of risk, when prioritizing between risk- reducing policies and legislation ${ }^{(15,46,59)}$. There is, therefore, a chance that hazards are not prioritized in an optimal way, with too much focus and resources allocated to some specific risks and other hazards not given the proper attention ${ }^{(60,2)}$. By understanding how individuals think and respond to risk, and learning more about the public's often present risk bias, policy makers have a better chance of designing effective risk policies and improving the cost effectiveness of risk policy ${ }^{(5)}$.

Another important policy implication of bias in risk perception is its indirect effect on benefitcost analysis (BCA). The benefit of reductions in premature mortality has been shown to be an important element in $\mathrm{BCA}^{(61,62)}$. But if, for instance, the public perceives risks to be higher than they actually are, monetary estimates of the value of risk reductions would be higher than if the public was better informed ${ }^{(2,3)}$. There is extensive, and "strong and quite diverse" (44) evidence that individuals are rational in their decision-making involving risks in the market ${ }^{(63)}$, but there are also results which imply that the estimated "risk-dollar" tradeoffs may not always be accurate ${ }^{(64)}$. When hypothetical markets are used to elicit individuals' WTP, there is evidence of ordinal but not cardinal risk comprehension ${ }^{(65)}$. Hence, individuals seem to respond in a correct way to risks, both in hypothetical and market scenarios, but "their ability to perceive risk in a cardinally correct way is questioned" (66).

It is well established that individuals experi- 
ence difficulties when evaluation uncertain events, for instance gambles and health or environmental risks. In addition to the problem of incomplete and costly information individuals are often driven by, e.g., emotions, heuristics, cultural factors, and may have cognitive constraints processing all the information, when forming their perceptions about risks and uncertain outcomes $(1,18,46,67)$. Therefore, when individuals compare the benefits and the costs of risky activities to achieve an optimal risk level their decisions are often based on biased risk beliefs ${ }^{(67,68)}$. This study contribute important knowledge about individuals' perception of their own mortality risk which further helps us understand biases and formation of risk perception. In decisions about risks, however, not only the risk perception is based on individual judgement but also the outcome. This paper has not addressed the latter. Future research on the perception of possible gains and losses would therefore be of interest to better understand individual decision making under risk.

\section{ACKNOWLEDGEMENTS}

Financial support from VTI, VINNOVA, the Centre for Transport Studies, Stockholm, and La Fondation Jean-Jacques Laffont is gratefully acknowledged. The author is also grateful to four anonymous reviewers for their helpful comments on an earlier draft. The usual disclaimers apply.

\section{APPENDIX: ARITHMETIC MEANS AND MULTINOMINAL LOGIT}

[Table VI about here.]

[Table VII about here.]

\section{REFERENCES}

1. Slovic P. The Perception of Risk. London, UK: Earthscan; 2000.

2. Gayer T, Hamilton JT, Viscusi WK. Private Values of Risk Tradeoffs at Superfund Sites: Housing Market Evidence on Learning About Risk. Review of Economics and Statistics. 2000;82(3):439-451.

3. Bleichrodt H, Eeckhoudt L. Willingness to pay for reductions in health risks when probabilities are distorted. Health Economics Letters. 2006;15(2):211-214.

4. Hakes JK, Viscusi WK. Mortality Risk Perceptions: A Bayesian Reassessment. Journal of Risk and Uncertainty. 1997;15(2):135-150.

5. Hakes JK, Viscusi WK. Dead Reckoning: Demographic Determinants of the Accuracy of Mortality Risk Perception. Risk Analysis. 2004;24(3):651-664.

6. Lichtenstein S, Slovic P, Fischhoff B, Layman M, Combs B. Judged Frequency of Lethal Events. Journal of Experimental Psychology: Human Learning and Memory. 1978;4(6):551-578.

7. Morgan MG, et al . On Judging the Frequency of Lethal Events: A Replication. Risk Analysis. 1983;3(1):11-16.

8. Viscusi WK, Hakes JK, Carlin A. Measures of Mortality Risks. Journal of Risk and Uncertainty. 1997;14(3):213233.

9. Armantier O. Estimates of own lethal risks and anchoring effects. Journal of Risk and Uncertainty. 2006;32(1):3756.

10. Benjamin D, Dougan WR. Individuals' Estimates of the Risks of Death: Part I - A Reassessment of the Previous Evidence. Journal of Risk and Uncertainty. 1997;15(2):115-133.

11. Benjamin D, Dougan WR, Buschena D. Individuals' Estimates of the Risks of Death: Part II - New Evidence. Journal of Risk and Uncertainty. 2001;22(1):35-57.

12. Lundborg P, Andersson H. Gender, risk perceptions, and smoking behavior. Journal of Health Economics. 2008;27(5):1299-1311.

13. Viscusi WK. Are Individuals Bayesian Decision Makers? American Economic Review. 1985;75(2):381-385.

14. Andersson H, Lundborg P. Perception of own death risk: An analysis of road-traffic and overall mortality risks. Journal of Risk and Uncertainty. 2007;34(1):67-84.

15. Sunstein CR. Risk and Reason. Cambridge, UK: Cambridge University Press; 2002.

16. Slimak MW, Dietz T. Personal Values, Beliefs, and Ecologicial Risk Perception. Risk Analysis. 2006;26(6):16891705.

17. Kahneman D, Tversky A. Prospect Theory: An Analysis of Decision Under Risk. Econometrica. 1979;47(2):263291.

18. Kahneman D, Slovic P, Tversky A. Judgement under Uncertainty: Heuristics and Biases. Kahneman D, Slovic P, Tversky A, editors. New York, NY, USA: Cambridge University Press; 1982. 
19. Slovic P. Perception of Risk. Science. 1987;236:280-285.

20. Viscusi WK. Age Variation in Risk Perceptions and Smoking Decisions. Review of Economics and Statistics. 1991;73(4):577-588.

21. Savage I. Demographic Influences on Risk Perceptions. Risk Analysis. 1993;13(4):413-420.

22. Liu JT, Hsieh CR. Risk Perception and Smoking Behaviour: Empirical Evidence from Taiwan. Journal of Risk and Uncertainty. 1995;11(2):139-157.

23. Davidson DJ, Freudenberg WR. Gender and Environmental Risk Concerns: A Review and Analysis of Available Reserach. Environment and Behavior. 1996;28(3):302339 .

24. Antoñanzas F, Viscusi WK, Joan Rovira J, Braña FJ, Portillo F, Carvalho I. Smoking Risks in Spain: Part I Perceptions of Risks to the Smoker. Journal of Risk and Uncertainty. 2000;21(2-3):161-186.

25. Dosman DM, Adamowicz WL, Hrudey SE. Socioeconomic Determinats of Health- and Food Safety-Related Risk Perceptions. Risk Analysis. 2001;21(2):307-317.

26. Brown SL, Cotton A. Risk-Mitigating Beliefs, Risk Estimates, and Self-Reported Speeding in a Sample of Australian Drivers. Journal of Safety Research. 2003;34(2):183-188.

27. Lundborg P, Lindgren B. Do They Know What They are Doing? Risk Perceptions and Smoking Behavior Among Swedish Teenagers. Journal of Risk and Uncertainty. 2004;28(3):261-286.

28. Flynn J, Slovic P, Mertz CK. Gender, race and perception of environmental health risks. Risk Analysis. 1994;14(6):1101-1108.

29. Finucane ML, Slovic P, Mertz CK, Flynn J, Satterfield TA. Gender, Race, and Perceived Risk: The "White Male" Effect. Health, Risk \& Society. 2000;2(2):159-172.

30. Barke RP, Jenkins-Smith H, Slovic P. Risk Perceptions of Men and Women Scientists. Social Science Quarterly. 1997;78(1):167-176.

31. Slovic P, Malmfors T, Mertz CK, Neil N, Purchase IFH. Evaluating Chemical Risks: Results of a Survey of the British Toxicology Society. Human \& Experimental Toxicology. 1997;16:289-304.

32. Steger MAE, Witt SL. Gender Differences in Environmental Orientations: A Comparison of Publlics and Activists in Canada and the U.S. Western Political Quarterly. 1989;42(4):627-649.

33. Powell M, Ansic D. Gender differences in risk behavior in financial decision-making: An experimental analysis. Journal of Economic Psychology. 1997;18(6):605-628.

34. Jianakoplos NA, Bernasek A. Are women more risk averse? Economic Inquiry. 1998;36(4):620-630.

35. Hersch J. Compensating differentials for genderspecific job injury risks. American Economic Review. 1998;88(3):598-607.

36. Dickie M, Gerking S. Formation of Risk Beliefs, Joint Production and Willingness to Pay to Avoid Skin Cancer. Review of Economics and Statistics. 1996;78(3):451-463.

37. Matthews ML, Moran AR. Age Differences in Male Drivers' Perception of Accident Risk: The Role of Perceived Driving Ability. Accident Analysis and Prevention. $1986 ; 18(4): 299-313$.

38. Weinstein ND. Optimistic Biases About Personal Risks. Science. 1989;246:1232-1233.

39. DeJoy DM. An Examination of Gender Differences in Traffic Accident Risk Perception. Accident Analysis and Prevention. 1992;24(3):237-246.

40. Glendon AI, Dorn L, Davies DR, Matthews G, Taylor RG. Age and Gender Differences in Perceived Accident Likelihood and Driver Competences. Risk Analysis. $1996 ; 16(6): 755-762$.
41. Rafaely V, Meyer J, Zilberman-Sandler I, Viener S. Perception of traffic risks for older and younger adults. Accident Analysis and Prevention. 2008;40:697-703.

42. Rosenblom T, Shahar A, Elharar A, Danino O. Risk perception of driving as a function of advanced training aimed at recognizing and handling risks in demanding driving situations. Accident Analysis and Prevention. 2008;40:697-703.

43. Smith VK, Johnson FR. How do Risk Perceptions Respond to Information? The Case of Radon. Review of Economics and Statistics. 1988;70(1):1-8.

44. Viscusi WK. Fatal Tradeoffs: Public \& Private Responsibilities for Risk. New York, NY, USA: Oxford University Press; 1992.

45. Viscusi WK. Prospective Reference Theory: Toward an Explanation of the Paradoxes. Journal of Risk and Uncertainty. 1989;2(3):235-263.

46. Viscusi WK. Rational Risk Policy. New York, NY, USA: Oxford University Press; 1998.

47. Sundström K, Andersson H. Swedish Consumers' Willingness to Pay for Food Safety - a Contingent Valuation Study on Salmonella Risk. Lund, Sweden, Swedish Institute for Food and Agricultural Economics (SLI); 2009. Working Paper 2009:2.

48. Andersson H, Hammitt JK, Lindberg G, Sundström K. Willingness to Pay for Car Safety: Sensitivity to Time Framing. Stockholm, Sweden: VTI, Dept. of Transport Economics; 2008. Working Paper 2008:8.

49. Corso PS, Hammitt JK, Graham JD. Valuing MortalityRisk Reduction: Using Visual Aids to Improve the Validity of Contingent Valuation. Journal of Risk and Uncertainty. 2001;23(2):165-184.

50. Atkinson SE, Halvorsen R. The Valuation of Risks to Life: Evidence from the Market for Automobiles. Review of Economics and Statistics. 1990;72(1):133-136.

51. Dreyfus MK, Viscusi WK. Rates of Time Preference and Consumer Valuations of Automobile Safety and Fuel Efficiency. Journal of Law and Economics. 1995;38(1):79105 .

52. Andersson H. The Value of Safety as Revealed in the Swedish Car Market: An Application of the Hedonic Pricing Approach. Journal of Risk and Uncertainty. 2005;30(3):211-239.

53. Rydenstam K. Mer jämställt i Norden än i öriga Europa?; 2008. SCB:s tidskrift Välfärd, Nr 1.

54. EuroQol Group. A New Facility for the Measurement of Health-Related Quality of Life. Health Policy. 1990;16:199-208.

55. Elvik R, Vaa T. The Handbook of Road Safety Measures. Oxford, UK: Elsevier; 2004.

56. Lundborg P. Smoking, information sources, and risk perception - New results on Swedish data. Journal of Risk and Uncertainty. 2007;34(3):217-240.

57. Khwaja A, Sloan F, Chung S. The relationship between individual expectations and behaviors: Mortality expectations and smoking decisions. Journal of Risk and Uncertainty. 2007;35:179-201.

58. Deery HA. Hazard and Risk Perception among Young Novice Drivers. Journal of Safety Research. 1999;30(4):225-236.

59. Slovic P. Trust, Emotion, Sex, Politics, and Science: Surveying the Risk-Assessment Battlefield. Risk Analysis. 1999;19(4):689-701.

60. Tengs TO, Adams ME, Pliskin JS, Safran DG, Siegel JE, Weinstein MC, et al. Five-Hundred Life-Saving Interventions and Their Cost-Effectiveness. Risk Analysis. 1995;15(3):369-390.

61. US EPA. The Benefits and Costs of the Clean Air Act, 1990-2010. US Environmental Protection Agency; 1999. 
62. US EPA. Arsenic in Drinking Water Rule: Economic Analysis. US Environmental Protection Agency; 2000. EPA 815-R-00-026.

63. Viscusi WK, Aldy JE. The Value of a Statistical Life: A Critical Review of Market Estimates Throughout the World. Journal of Risk and Uncertainty. 2003;27(1):5-76.

64. Viscusi WK, Magat WA. Learning about Risk: Consumer and Worker Response to Hazard Warnings. Cambridge, MA, USA: Harvard University Press; 1987.

65. Hammitt JK, Graham JD. Willingness to Pay for Health Protection: Inadequate Sensitivity to Probability? Journal of Risk and Uncertainty. 1999;18(1):33-62.

66. Blomquist GC. Self-Protection and Averting Behavior, Values of Statistical Lives, and Benefit Cost Analysis of Environmental Policy. Review of Economics of the Household. 2004;2(1):89-110.

67. Vlek C. Environmental Versus Individual Risk Taking: Perception, Decision, Behavior. In: Spielberger C, editor. Encyclopedia of Applied Psychology. New York: Elsevier; 2004. p. 825-840.

68. Vlek C, Stallen PJ. Rational and Personal Aspects of Risk. Acta Psychologica. 1980;45:273-300.

69. Andersson H. Willingness to Pay for Road Safety and Estimates of the Risk of Death: Evidence from a Swedish Contingent Valuation Study. Accident Analysis and Prevention. 2007;39(4):853-865.

70. Koltowska-Häggström M, Jonsson B, Isacson D, Bingefors K. Using EQ-5D To Derive Utilities For The Quality Of Life - Assessment Of Growth Hormone Deficiency In Adults (QoL-AGHDA). Value in Health. 2007;10(1):7381.

71. Brooks RG, Jendteg S, Lindgren B, Persson U, Björk S. EuroQol: Health-Realted Quality of Life Measurement. Results of the Swedish Questionnaire Exercise. Health Policy. 1991;18:37-48. 
Fig. 1. Nature of updating process. Source: Viscusi (1992)

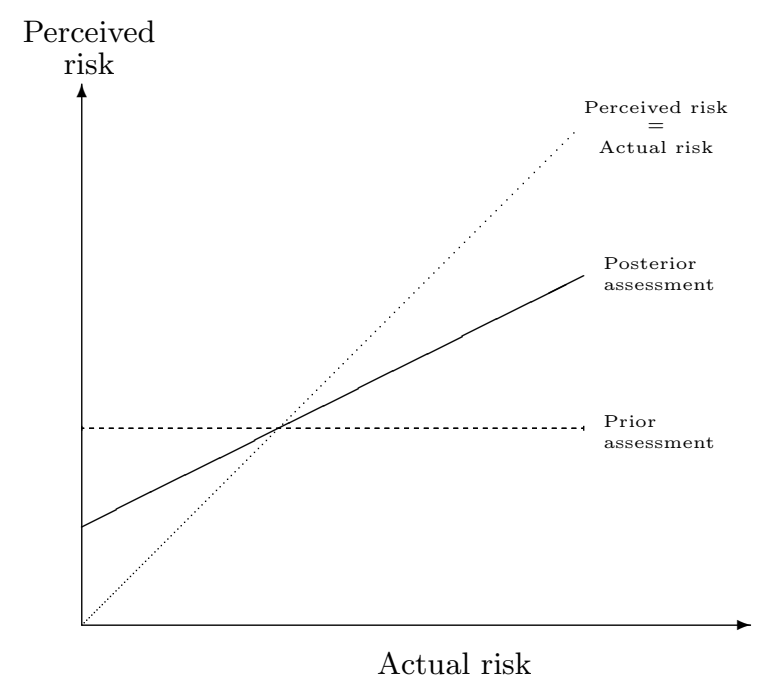

Fig. 2. Scatterplot perceived and actual risk (Perceived $<40 / 100,000)$

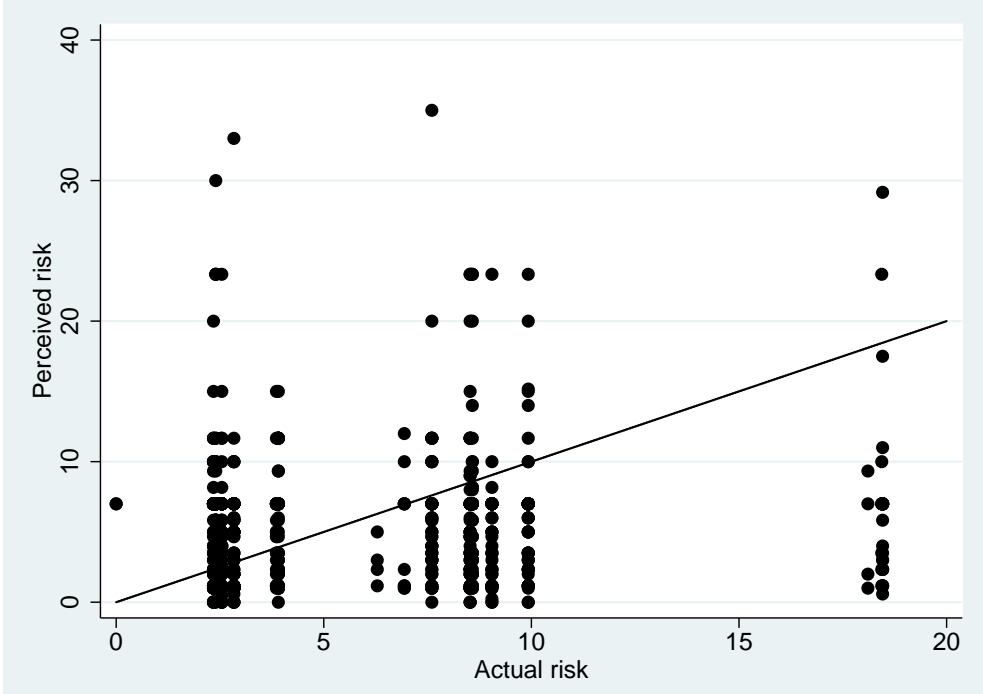


Table I . Summary statistics

\begin{tabular}{|c|c|c|c|c|c|}
\hline \multirow[b]{2}{*}{ Variable } & \multirow[b]{2}{*}{ Description } & \multicolumn{3}{|c|}{ Survey } & \multirow{2}{*}{$\begin{array}{r}\text { Sweden } \\
\text { Mean }\end{array}$} \\
\hline & & Mean & Std. Dev. & $\mathbf{N}$ & \\
\hline Road mortality & Risk perception & 57.504 & 829.769 & 818 & - \\
\hline Road bias & $\begin{array}{l}\text { Difference between objective and } \\
\text { perceived risk in absolute terms. }\end{array}$ & 51.594 & 829.725 & 818 & - \\
\hline Road underassess & $\begin{array}{l}\text { Dummy coded as one if respondents' perceived risk } \\
\text { lower than objective risk for own age and gender. }\end{array}$ & 0.507 & 0.5 & 893 & - \\
\hline Age & Age of respondent. & 46.583 & 15.439 & 893 & $44.7^{\mathrm{b}}$ \\
\hline Health status & Respondent's self-reported health status. & 89.093 & 12.265 & 842 & $-{ }^{c}$ \\
\hline Female & Dummy coded as one if female. & 0.575 & 0.495 & 891 & $49.6^{\mathrm{b}}$ \\
\hline Income & Net monthly household income. (SEK) & 25,455 & 13,348 & 880 & 22,639 \\
\hline Annual mileage & $\begin{array}{l}\text { Annual mileage by car (as driver and/or } \\
\text { passenger, } 1 \text { mile }=10 \text { kilometers). }\end{array}$ & 1,307 & 812 & 872 & 1,390 \\
\hline University & Dummy equal to one if university degree. & 0.367 & 0.482 & 881 & 0.35 \\
\hline Own accident & $\begin{array}{l}\text { Dummy coded as one if respondent has been } \\
\text { injured in a traffic accident. }\end{array}$ & 0.076 & 0.264 & 874 & - \\
\hline Family accident & $\begin{array}{l}\text { Dummy coded as one if someone in respondent's } \\
\text { household has been injured in a traffic accident. }\end{array}$ & 0.108 & 0.31 & 864 & - \\
\hline Household 0-3 & Number of household members $0-3$ years of age. & 0.121 & 0.371 & 840 & - \\
\hline Household 4-10 & Number of household members $4-10$ years of age. & 0.232 & 0.66 & 840 & - \\
\hline Household 11-17 & Number of household members $11-17$ years of age. & 0.354 & 0.853 & 840 & - \\
\hline Risk correct & $\begin{array}{l}\text { Dummy equal to one if respondent ranked five } \\
\text { fatality risks correctly. }{ }^{\text {a }}\end{array}$ & 0.235 & 0.425 & 879 & - \\
\hline Driving licence & $\begin{array}{l}\text { Dummy coded as one if respondent has } \\
\text { a driving licence. }\end{array}$ & 0.882 & 0.323 & 882 & 0.82 \\
\hline Access car & $\begin{array}{l}\text { Dummy coded as one if respondent has } \\
\text { access to a car in his/her household. }\end{array}$ & 0.881 & 0.324 & 859 & 0.74 \\
\hline
\end{tabular}

All prices are in 2006 price level. USD 1 = SEK 7.38 (www.riksbank.se, 2/11/2008)

a: The hazards were "Heart and vascular diseases", "Lung cancer", "Car accidents", "AIDS/HIV", and

"Food contamination".

b: Age group 18-74.

c: Mean estimates from three other Swedish studies using the same VAS measure, $84.14^{(69)}$, $85^{(70)}$, and $85.37^{(71)}$.

Table II . Geometric mean road-mortality risk per 100,000 by sex and age groups Objective risk $^{a} \quad$ Perceived risk

\begin{tabular}{|c|c|c|c|c|c|c|c|c|c|}
\hline Age group & Female & Male & Total & Female & $\mathbf{N}$ & Male & $\mathbf{N}$ & Total & $\mathbf{N}$ \\
\hline $18-19$ & 6.94 & 18.44 & 12.84 & $5.65^{b}$ & 12 & 5.44 & 8 & 5.57 & 20 \\
\hline $20-24$ & 3.86 & 18.46 & 11.31 & $4.33^{b}$ & 30 & 7.60 & 30 & 5.73 & 60 \\
\hline $25-34$ & 2.54 & 9.93 & 6.31 & 4.88 & 78 & 5.12 & 62 & 4.99 & 140 \\
\hline $35-44$ & 2.40 & 8.58 & 5.56 & 5.22 & 105 & 5.76 & 60 & $5.41^{b}$ & 165 \\
\hline $45-54$ & 2.34 & 7.60 & 5.00 & 4.70 & 79 & $5.91^{b}$ & 63 & 5.21 & 143 \\
\hline $55-64$ & 2.84 & 8.53 & 5.69 & 4.29 & 87 & 5.50 & 78 & $4.84^{b}$ & 166 \\
\hline $65-74$ & 3.91 & 9.05 & 6.33 & $4.08^{b}$ & 53 & 4.46 & 52 & $4.27^{b}$ & 105 \\
\hline $\begin{array}{l}\text { Overall mean } \\
(95 \% \text { C.I. })\end{array}$ & 2.96 & 9.86 & 6.42 & $\begin{aligned} & 4.68 \\
&(4.23:\end{aligned}$ & $\begin{array}{l}444 \\
6.19)\end{array}$ & $\begin{array}{r}5.53 \\
(4.87:\end{array}$ & $\begin{array}{r}353 \\
6.27)\end{array}$ & $\begin{array}{r}5.04 \\
(4.65:\end{array}$ & $\begin{array}{r}797 \\
5.46)\end{array}$ \\
\hline
\end{tabular}

$a$ : Objective risk calculated on data from 1999-2006 (www.sika-institute.se, 10/10/07).

$b$ : Not statistically significantly different from corresponding objective risk (95\% C.I.).

$c: \mathrm{H}_{0}:$ Perceived $($ Female $)=$ Perceived $($ Male $)$ 
Table III . Probability of underassessment of mortality risk

\begin{tabular}{lcc}
\hline Variable & Coeff. & \\
\hline Age 25-34 & 0.0729 & $(0.0847)$ \\
Age 35-44 & 0.0318 & $(0.0852)$ \\
Age 45-54 & 0.0485 & $(0.0844)$ \\
Age 55-64 & 0.0162 & $(0.0854)$ \\
Age 65-74 & 0.0850 & $(0.0917)$ \\
Health status & $1.42 \mathrm{e}-04$ & $(0.00196)$ \\
Female & $-0.598^{* *}$ & $(0.0319)$ \\
Income & $7.12 \mathrm{e}-08$ & $(1.81 \mathrm{e}-06)$ \\
Annual mileage & $-5.34 \mathrm{e}-05^{\dagger}$ & $(3.03 \mathrm{e}-05)$ \\
University & -0.0598 & $(0.0466)$ \\
Own accident & -0.100 & $(0.0918)$ \\
Family accident & -0.0138 & $(0.0799)$ \\
Household 0-3 & $-0.141^{*}$ & $(0.0639)$ \\
Household 4-10 & $0.0736^{\dagger}$ & $(0.0423)$ \\
Household 11-17 & -0.0270 & $(0.0320)$ \\
Risk correct & -0.0107 & $(0.0520)$ \\
Driving licence & $-0.180^{*}$ & $(0.0706)$ \\
Access car & -0.0971 & $(0.0798)$ \\
\hline$N$ & \multicolumn{3}{c}{711} \\
$\tilde{\mathrm{R}}^{2}$ & \multicolumn{2}{c}{0.265} \\
\hline Significance levels : & $\dagger: 10 \%$ & $*$ * $5 \%$ \\
Robust standard errors in parentheses \\
The coefficient estimates denote marginal effects.
\end{tabular}


Table IV . Risk bias for over- and underassessors

\begin{tabular}{|c|c|c|c|c|}
\hline \multirow[b]{2}{*}{ Variable } & \multicolumn{2}{|c|}{ Sub. risk $<$ Obj. risk } & \multicolumn{2}{|c|}{ Sub. risk $\geq$ Obj. risk } \\
\hline & Coeff. & (Std. Err.) & Coeff. & (Std. Err.) \\
\hline Age $25-34$ & $-5.899^{* *}$ & $(0.778)$ & 161.461 & $(212.142)$ \\
\hline Age $35-44$ & $-7.015^{* *}$ & $(0.802)$ & -24.418 & $(125.365)$ \\
\hline Age $45-54$ & $-6.984^{* *}$ & $(0.805)$ & 70.527 & $(144.086)$ \\
\hline Age $55-64$ & $-6.333^{* *}$ & $(0.783)$ & 430.810 & $(485.543)$ \\
\hline Age $65-74$ & $-5.960 * *$ & $(0.796)$ & 6.920 & $(159.359)$ \\
\hline Health status & -0.006 & $(0.011)$ & 1.919 & $(2.836)$ \\
\hline Female & $-3.710^{* *}$ & $(0.292)$ & -590.492 & $(426.591)$ \\
\hline Income & $1.08 \mathrm{e}-05$ & $(1.43 \mathrm{e}-05)$ & -0.003 & $(0.002)$ \\
\hline Annual mileage & $2.67 \mathrm{e}-04$ & $(1.93 \mathrm{e}-04)$ & -0.173 & $(0.121)$ \\
\hline University & $-0.527^{\dagger}$ & $(0.298)$ & -107.810 & $(93.564)$ \\
\hline Own accident & -0.470 & $(0.540)$ & -169.215 & $(144.668)$ \\
\hline Family accident & 0.239 & $(0.457)$ & -61.425 & $(86.840)$ \\
\hline Household 0-3 & -0.163 & $(0.584)$ & 0.399 & $(52.486)$ \\
\hline Household 4-10 & -0.277 & $(0.240)$ & 70.369 & $(71.332)$ \\
\hline Household 11-17 & 0.104 & $(0.166)$ & 189.625 & $(151.081)$ \\
\hline Risk correct & -0.104 & $(0.313)$ & 17.642 & $(104.224)$ \\
\hline Driving licence & -0.657 & $(0.495)$ & 320.678 & $(276.211)$ \\
\hline Access car & 0.136 & $(0.498)$ & -739.322 & $(765.760)$ \\
\hline Intercept & $12.262^{* *}$ & (1.208) & 957.908 & (736.153) \\
\hline $\mathrm{N}$ & \multicolumn{2}{|r|}{350} & \multicolumn{2}{|r|}{317} \\
\hline $\mathrm{R}^{2}$ & \multicolumn{2}{|c|}{0.572} & \multicolumn{2}{|c|}{0.099} \\
\hline $\begin{array}{l}\text { Significance levels : } \\
\text { Robust standard }\end{array}$ & $\begin{array}{l}\dagger: 10 \% \\
\text { rrors in }\end{array}$ & $\begin{array}{l}: 5 \% \quad * *: 1 \% \\
\text { rentheses }\end{array}$ & & \\
\hline
\end{tabular}


Table V . Risk perception formation

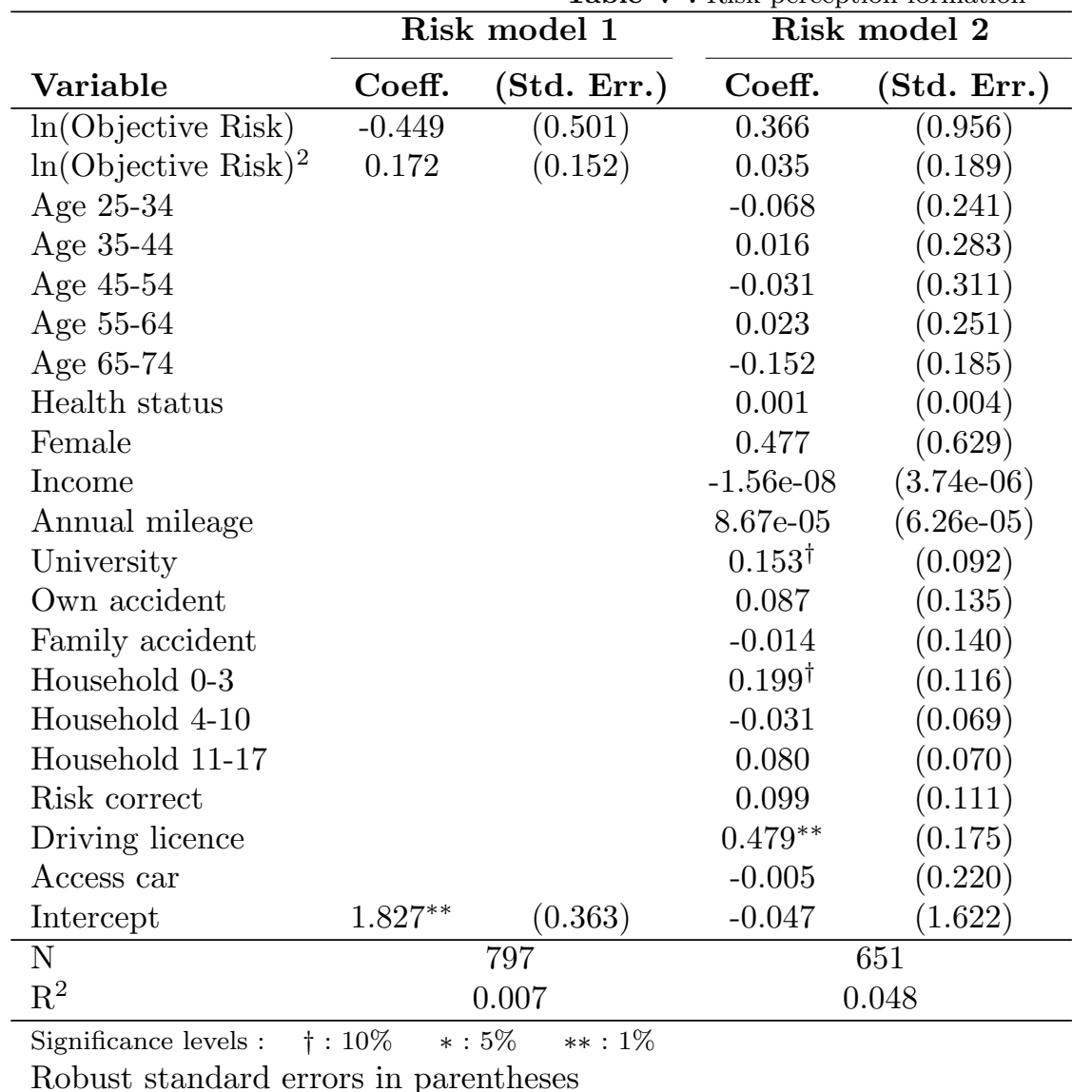

Table VI . Arithmetic mean road-mortality risk per 100,000 by sex and age groups

\begin{tabular}{|c|c|c|c|c|c|c|c|c|c|}
\hline \multirow[b]{2}{*}{ Age group } & \multicolumn{3}{|c|}{ Objective risk ${ }^{a}$} & \multicolumn{6}{|c|}{ Perceived risk } \\
\hline & Female & Male & Total & Female & $\mathbf{N}$ & Male & $\mathbf{N}$ & Total & $\mathbf{N}$ \\
\hline $18-19$ & 6.94 & 18.44 & 12.84 & $101.94^{b}$ & 12 & 7.67 & 8 & $64.23^{b}$ & 20 \\
\hline $20-24$ & 3.86 & 18.46 & 11.31 & 5.36 & 30 & $53.84^{b}$ & 30 & $29.60^{b}$ & 60 \\
\hline $25-34$ & 2.54 & 9.93 & 6.31 & $21.89^{b}$ & 80 & $7.29^{b}$ & 64 & $15.40^{b}$ & 144 \\
\hline $35-44$ & 2.40 & 8.58 & 5.56 & 8.61 & 106 & $12.45^{b}$ & 60 & 10.00 & 166 \\
\hline $45-54$ & 2.34 & 7.60 & 5.00 & $147.00^{b}$ & 83 & $88.07^{b}$ & 64 & $120.57^{b}$ & 148 \\
\hline $55-64$ & 2.84 & 8.53 & 5.69 & 7.11 & 90 & $256.61^{b}$ & 81 & $124.61^{b}$ & 172 \\
\hline $65-74$ & 3.91 & 9.05 & 6.33 & 5.42 & 54 & $9.83^{b}$ & 54 & $7.63^{b}$ & 108 \\
\hline $\begin{array}{l}\text { Overall mean } \\
\text { (95\% C.I.) }\end{array}$ & 2.96 & 9.86 & 6.42 & $\begin{array}{c}37.76 \\
(-13.08:\end{array}$ & $\begin{array}{l}455 \\
8.61)\end{array}$ & $\begin{array}{r}82.67 \\
(-29.64\end{array}$ & $\begin{array}{r}361 \\
194.97)\end{array}$ & $\begin{array}{c}57.63 \\
(0.54: 1\end{array}$ & $\begin{array}{r}816 \\
4.71)\end{array}$ \\
\hline
\end{tabular}

a: Objective risk calculated on data from 1999-2006 (www.sika-institute.se, 10/10/07).

$b$ : Not statistically significantly different from corresponding objective risk (95\% C.I.).

$c: \mathrm{H}_{0}:$ Perceived $($ Female $)=$ Perceived $($ Male $)$ 
Table VII . Multinominal logit

\begin{tabular}{|c|c|c|c|c|}
\hline \multirow[b]{2}{*}{ Variable } & \multicolumn{2}{|c|}{ Underassessors } & \multicolumn{2}{|c|}{ Overassessors } \\
\hline & Coeff. & (Std. Err.) & Coeff. & (Std. Err.) \\
\hline Age 25-34 & 0.420 & $(0.527)$ & 0.215 & $(0.555)$ \\
\hline Age $35-44$ & $1.183^{*}$ & $(0.547)$ & $1.197^{*}$ & $(0.545)$ \\
\hline Age 45-54 & 0.029 & $(0.538)$ & 0.227 & $(0.519)$ \\
\hline Age 55-64 & 0.651 & $(0.540)$ & 0.754 & $(0.571)$ \\
\hline Age $65-74$ & $1.298^{*}$ & $(0.647)$ & 0.859 & $(0.683)$ \\
\hline Health status & -0.004 & $(0.014)$ & -0.006 & $(0.013)$ \\
\hline Female & $-2.098^{* *}$ & $(0.334)$ & $1.048^{* *}$ & $(0.337)$ \\
\hline Income & $-8.71 \mathrm{e}-06$ & $(1.16 \mathrm{e}-05)$ & $-4.31 \mathrm{e}-06$ & $(1.14 \mathrm{e}-05)$ \\
\hline Annual mileage & $1.04 \mathrm{e}-04$ & $(1.92 \mathrm{e}-04)$ & $1.18 \mathrm{e}-04$ & $(1.87 \mathrm{e}-04)$ \\
\hline University & -0.125 & $(0.313)$ & 0.225 & $(0.296)$ \\
\hline Own accident & -0.983 & $(0.636)$ & -0.215 & $(0.599)$ \\
\hline Family accident & $1.288^{*}$ & $(0.655)$ & 0.899 & $(0.679)$ \\
\hline Household 0-3 & -0.152 & $(0.428)$ & 0.568 & $(0.395)$ \\
\hline Household 4-10 & -0.344 & $(0.264)$ & $-0.422^{\dagger}$ & $(0.232)$ \\
\hline Household 11-17 & -0.151 & $(0.206)$ & 0.051 & $(0.190)$ \\
\hline Risk correct & 0.300 & $(0.388)$ & 0.410 & $(0.372)$ \\
\hline Driving licence & $-1.362^{*}$ & $(0.583)$ & -0.383 & $(0.562)$ \\
\hline Access car & 0.394 & $(0.487)$ & 0.536 & $(0.494)$ \\
\hline Intercept & $3.680^{* *}$ & (1.394) & 0.319 & $(1.342)$ \\
\hline $\mathrm{N}$ & \multicolumn{4}{|c|}{667} \\
\hline$\tilde{\mathrm{R}}^{2}$ & \multicolumn{4}{|c|}{218.648} \\
\hline $\begin{array}{l}\text { Significance levels : } \\
\text { Accurate risk per } \\
\text { Perceived } \in[\mathrm{Obj} \text {. }\end{array}$ & $\begin{array}{l}\dagger: 10 \% \\
\text { eption is } \\
1, \mathrm{Obj} .\end{array}$ & $\begin{array}{ll}5 \% & * *: 1 \% \\
\text { base outcom }\end{array}$ & & \\
\hline
\end{tabular}

